\title{
Flame Characteristics of Pulverized Torrefied-Biomass Combusted with
}

\author{
High-Temperature Air \\ Jun $\mathrm{Li}^{* 1}$, Enrico Biagini ${ }^{2}$, Weihong Yang ${ }^{1}$, Leonardo Tognotti ${ }^{2,3}$, Wlodzimierz Blasiak ${ }^{1}$ \\ ${ }^{1}$ Division of Energy and Furnace Technology, KTH-Royal Institute of Technology, \\ Brinellvägen 23, 10044 Stockholm, Sweden \\ Tel: +46 8 7908458; Fax: +46 82076 81; Email: jun2@kth.se \\ ${ }^{2}$ International Flame Research Foundation, Via Salvatore Orlando 5, 57123 Livorno, Italy \\ ${ }^{3}$ Dipartimento di Ingegneria Chimica, Universitá di Pisa, Via Diotisalvi 2, 56100 Pisa, Italy
}

\section{Abstract:}

In this work, the flame characteristics of torrefied biomass were studied numerically under hightemperature air conditions to further understand the combustion performances of biomass. Three torrefied biomasses were prepared with different torrefaction degrees after by releasing $10 \%, 20 \%$, and $30 \%$ of volatile matter on a dry basis and characterized in laboratory with standard and high heating rate analyses. The effects of the torrefaction degree, oxygen concentration, transport air velocity, and particle size on the flame position, flame shape, and peak temperature are discussed based on both direct measurements in a laboratory-scale furnace and CFD simulations. The results primarily showed that the enhanced drag force on the biomass particles caused a late release of volatile matter and resulted in a delay in the ignition of the fuelair mixture, and the maximum flame diameter was mainly affected by the volatile content of the biomass materials. Furthermore, oxidizers with lower oxygen concentrations always resulted in a larger flame volume, a lower peak flame temperature and a lower NO emission. Finally, a longer flame was found when the transport air velocity was lower, and the flame front gradually moved to the furnace exit as the particle size increased. The results could be used as references for designing a new biomass combustion chamber or switching an existing coal-fired boiler to the combustion of biomass.

Key words: Torrefaction; Pulverized solid biomass; CFD; Flame; High temperature 


\section{Introduction}

It has been widely recognized that biomass has the potential to fulfill the increasing energy demands and the strict regulations on $\mathrm{CO}_{2}$ emissions [1]. Sweden has set a target to create the first oil-free economy in the world by 2020 , and today, approximately $21 \%$ of the total heat of consumption in Sweden is provided by biomass and biofuels [2]. Currently, the combustion of biomass is acknowledged to be a cheaper, lower risk, and more technically complete option compared to other biomass thermal conversion technologies. The combustion behavior of biomass is different from that of coal. Firstly, biomass yields a much higher fraction of volatiles through its devolatilization process. In addition, the low density of biomass results in the higher oxidization rate of biomass char. Therefore, although a lower replacement ratio of biomass in cofiring boilers shows relatively few operational problems[3], the co-firing of greater than $20 \%$ of biomass (on an energy basis) in existing large-scale pulverized coal boilers without modifications usually results in unstable boiler efficiency and fluctuations of the boiler load.

Torrefied biomass can be a suitable alternative fuel in existing large-scale pulverized coal boilers, because torrefaction changes the characteristics of biomass and moves it more similar to coal [4-9]. For example, torrefied biomass has higher energy content when compared to the parent material, the lower fibrous content makes it easy and energy-efficient to grind the torrefied materials, torrefied biomass powder have high flowability and good fluidization behavior and biomass is increasingly uniform after torrefaction. Accordingly, a torrefaction-based co-firing system in pulverized coal boilers has been proposed as a promising option with the aim of $100 \%$ of biomass fuel switching[10,11].

When co-firing torrefied biomass in an existing pulverized coal boiler, the biomass flame characteristics are important when selecting the burner for biomass combustion from existing burners, and also may provide an operational reference for fuel switching. Several previous works have attempted to study the differences between the combustion of pulverized coal and biomass, 
or the effects of co-firing on flame characteristics and stability. Lu et al. [3] suggested that the addition of biomass affected the flame characteristics, particularly the flame ignition points and brightness, due to the variation in the physical and chemical properties of the biomass fuels. Ballester et al. [12] compared pulverized coal flames and pulverized sawdust flames in a semiindustrial furnace under the same operating conditions and concluded that the combustion zone is extended further for the biomass. Molcan et al. [13] found that the addition of biomass to coal could improve the combustion efficiency because of the lower CO concentrations and higher char burnout levels in co-firing.

Computational fluid dynamics (CFD) has also been widely employed to study biomass combustion by compiling a comprehensive biomass combustion model. Mandø et al. [14] performed a CFD simulation of pulverized coal and straw combustion by using a commercial multi-fuel burner and concluded that straw combustion is associated with a significantly longer flame and smaller recirculation zones compared to coal. Yin et al. [15] numerically investigated the co-firing of a biomass suspension by studying the coal flame and the biomass flame in a swirlstabilized burner and reported that a greater amount of volatiles released from the straw resulted in a greater volume in the reactor prior to mixing with the oxidizer. Gubba et al. studied the influence of particle shape and the internal thermal gradients of the biomass particles on the cofired flames of pulverized coal and biomass [16]. Additionally, other CFD simulations have been performed on large-scale furnaces to investigate the effects of the co-firing ratio on boiler performances [10,17-19]. However, there has not been a comprehensive study on the effects of the torrefaction degree, fuel injection velocity, oxygen concentration, and particle size on biomass flame characteristics with the purpose of applying torrefied biomass in a large-scale furnace either for pure biomass combustion or for co-firing. The CFD modeling of biomass combustion still faces significant challenges because of the diversity of the biomass fuels and the lack of knowledge regarding their combustion properties[20]. In this work, the swelling behavior during devolatilization and the shape of torrefied biomasses have been experimentally studied and 
considered to accurately predict the particle trajectory and thus accurately predict the biomass flame and combustion properties.

Moreover, volumetric combustion has been proposed and developed to realize a high replacement ratio of biomass in co-firing boilers, which is expectedly accompanied by a reduction in pollutants [21]. The volumetric combustion of both gas and liquid fuels has been successfully realized for conditions of High Temperature Air Combustion (HTAC) [22-25]. Currently, several attempts have also been made to apply such technology in pulverized coal boilers [26, 27]. Such a volumetric combustion could be characterized as an extension of the HTAC technology to solid fuels. In this work, to further understand the combustion performance when switching a pulverized coal-fired boiler to combust biomass, the combustion and flame characteristics of torrefied biomass have been studied numerically in a laboratory-scale furnace at high temperature air conditions. Three torrefied biomasses and a primary coal were studied and a total of 17 cases were simulated with CFD, in which coal was employed for comparison and validation. Finally, the effects of the torrefaction degree, oxygen concentration, transport air velocity, particle size on the flame position, shape, and peak temperature are discussed.

\section{Methods}

\subsection{Fuel parameters and kinetic studies}

Three torrefied biomasses (TB) were prepared in previous, and were obtained from the same parent biomass, palm kernel shells (PKS), with different torrefaction degrees after releasing $10 \%, 20 \%$ and $30 \%$ of the volatile matter on a dry basis. For simplification, these biomasses are abbreviated as TB1, TB2, and TB3, respectively. The proximate and ultimate analyses data of the torrefied biomass samples and coal are shown in Table 1. It can be observed that torrefaction significantly reduces the volatile-to-fixed carbon ratio of the biomass and upgrades its energy density. 
The Van Krevelen diagram provides the relationship between $\mathrm{O} / \mathrm{C}$ and $\mathrm{H} / \mathrm{C}$ for different solid fuels, as shown in Figure 1. Three torrefied biomasses and a coal from this work are shown in this graph, while a bituminous coal, a sub-bituminous coal, a wood and the raw PKS are provided for reference. Figure 1 shows that the raw biomass has a lower energy density than coal; however, it interestingly shows that the energy density of the torrefied PKS becomes closer to that of bituminous coal as the torrefaction degree increases. Meanwhile, the breakdown of the fiber structure during torrefaction allowed the torrefied PKS samples to be grinded by the existing coal mill system. The coal particle size was assumed to follow the Rosin-Rammler distribution with an average diameter of $61.7 \mu \mathrm{m}$ and spread parameter of 4.21 , and the torrefied biomass particles were assumed to have the same sizes because they were grinded by the same mill system.

Figure 1.

To further understand the chemical properties of the torrefied biomass, thermogravimetric (TG) tests were performed in a TG balance. A TA-Q500 analyzer was used in constant heating rate tests under nitrogen (to temperature of $800^{\circ} \mathrm{C}$ ) for studying the pyrolysis step, followed by the oxidation in air for measuring the ash content. Furthermore, the devolatilization tests were carried out in an isothermal plug flow reactor (IPFR). The test conditions were set to be similar to industrial pulverized fuel applications, such as high temperature and high heating rates. The reactor used can represent the conditions found in full-scale combustion processes with heating rates on the order of $10^{4} \mathrm{C} / \mathrm{s}$, a maximum temperature of $1400{ }^{\circ} \mathrm{C}$, and particle residence time from 5 to $1500 \mathrm{~ms}$. A flow of $100 \mathrm{~g} / \mathrm{h}$ of biomass powder guaranteed stationary conditions for a time test of at least 30 minutes. The fuel conversion was evaluated by comparing the composition of the collected solid residue with that of the parent fuel by using the ash tracer method. 
After the devolatilization tests, a nominal temperature of $900{ }^{\circ} \mathrm{C}$ and residence time of 300 ms were used to produce a high heating-rate char and assure the complete devolatilization but prevent the graphitization of the carbonaceous matrix. The collected char residues of the torrefied biomass were tested in the ThermoGravimetric Balance to evaluate the intrinsic char oxidation kinetics. Small char samples $(3 \mathrm{mg}$ ) have been tested to limit material and thermal resistances during the tests. Three trials were carried out for each char sample at a constant heating rate $\left(20^{\circ} \mathrm{C} / \mathrm{min}\right)$ under different transport gas mixtures $(5 \%, 12 \%$, and $21 \%$ volume of oxygen, with the remainder nitrogen). In addition, the optical microscope images of a statistical number of particles were analyzed to obtain the morphological parameters of the shape factor and swelling coefficient, and all of the morphological studies referred to the planar outlines of each particle. More detailed procedures of biomass characterization were reported by Biagini et al.[28].

\subsection{Experimental methods}

The scheme for the pulverized fuel combustion facility is shown in Figure 2. The secondary air was heated to $1150{ }^{\circ} \mathrm{C}$ by a compact pre-heater and injected through the top of the chamber. The pulverized fuel was pneumatically conveyed into the furnace by transport air from a $5 \mathrm{~mm}$ vertical water-cooling lance. On the bottom of chamber, there was outlet for the flue gas. The temperature profile along the combustion chamber and the temperature at the inlet and the outlet were recorded using thermocouples. The tips of the thermocouples were located in the middle of the inlet and outlet channels, and all of the thermocouples tips installed on the furnace chamber were $200 \mathrm{~mm}$ from the wall. Two isokinetic probes were located in the flue gas channel to collect ash and sample flue gas. An ECO PHYSICS CLD 700 EL ht was used to measure the NOx, and the error of the measured $\mathrm{NOx}$ was less than $0.5 \%$ of the measuring range. Before each experiment, the test chamber was heated for 10-12 hours to achieve a uniform temperature profile inside the chamber. Two observation windows near the tip of the fuel lance allowed for the observation and recording of the flame behavior. 


\subsection{Flame parameters}

The physical characteristics of the flame, which include geometrical and luminous profiles, temperature distributions and oscillatory attributes, provided instantaneous information on the quality of the fuel, and thus the quality of the combustion process [3]. A more accurate and less subjective method was proposed to describe a flame based on the species concentrations; this type of flame was named as "chemical flame" [29]. The chemical flame of solid fuels and the flame parameters are schematized in Figure 3. All of the flame parameters based on the chemical flame data, including the flame lift-off distance, flame length and maximum flame diameter, are distinguished from the luminous flame parameters based on visual observations. In this work, the chemical flame was employed to describe the shape and position of a flame inside the furnace based on the following equation [29]:

$$
R_{O}=\frac{m_{O}}{m_{O}+\sum_{i} s \cdot m_{F, i}}
$$

where $R_{O}$ is the oxidation mixture ratio, $m$ is the mass fraction, and the subscripts $O$ and $F$ refer to oxygen and the combustible species, respectively. $s=n_{O} M_{O} / n_{F} M_{F}$, in which $n$ is the stoichiometric coefficient (number of moles) and $M$ is the molecular weight.

It was reported that the mechanism of pulverized coal flame propagation depends on the rate of appearance of combustible volatiles in front of the flame, and heterogeneous combustion is influenced by the rate of pyrolysis behind the flame[30]. Therefore, it is possible to employ the oxidation mixture ratio to describe the flame volume for pulverized fuel combustion. According to Yang et al. [29], the flame volume can be defined as $0 \leq R_{O} \leq R_{C}$ and the critical oxidation ratio of $R_{C}=0.99$ approximately represents the outside border of the flame. 


\subsection{CFD modeling}

Ansys Fluent 13.0 was used to simulate the combustion, fluid and particle flow, as well as the heat and mass transfer inside the furnace[31]. A cylindrical combustion chamber of $0.4 \mathrm{~m}$ inner diameter and $1.96 \mathrm{~m}$ height was modeled with a 3D geometry, as presented in Figure 2. The mesh independence was verified by comparing the reaction results. The mesh consisted of 73588 hexahedral cells and was refined in the zone of fuel injection, where the ignition and most of the combustion reactions occurred. In this work, the standard $k-\varepsilon$ model with a standard wall function was used to calculate the effect of turbulent flow[32]. The discrete ordinates (DO) radiation model was chosen to simulate the radiation heat transfer.

\section{(a) Combustion model}

The two-competing-rate model was employed to predict the biomass devolatilization rate and the volatile matter yield[33]. Even though the volatile matter contains many gaseous species, it was reasonable to represent the released volatile matter by a single virtual material, because the reaction rate of the volatile matter was limited by the turbulent mixing rate of the evolved gas and the oxidizer at the near-burner condition.

In high temperature air combustion cases, the maximum furnace temperature is as high as $1400{ }^{\circ} \mathrm{C}$, therefore, volatile combustion occurs at high Damköhler numbers (Da $\left.>>1\right)$. The type of volatile matter, which mainly consists of gas phase hydrocarbons, depends on the fuel type and the pyrolysis conditions. Two-step global combustion is used for the homogeneous combustion of gaseous volatiles and involves two overall reactions that were calculated using Eddy-Dissipation model[31]. The char combustion was determined by the minimum kinetic rate and diffusion rate[34, 35], and the diffusion coefficients for all cases were calculated using the following equation[36]:

$$
D_{0}=2.53 \times 10^{-7} T_{m}^{0.75} / d_{p}
$$


(b) Discrete phases model (DPM)

Both biomass particles and coal particles were modeled using the DPM approach. The trajectory of the discrete particle was calculated by integrating the force balance on the particle as in the motion equation[31]:

$$
\frac{d u_{P}}{d t}=\frac{18 \mu}{\rho_{P} \cdot d_{P}^{2}} \frac{C_{D} \cdot \operatorname{Re}}{24}\left(u-u_{P}\right)+\frac{g\left(\rho_{P}-\rho\right)}{\rho_{P}}
$$

Based on Eq. 3, the drag force has an important effect on the trajectory of discrete particles. The drag force coefficient, $C_{D}$, is a function of the particle shape factor $\Phi$ [37]. The shape factor is defined as the ratio of the surface area of a sphere with the same volume of the particle and the actual surface area. In this work, a non-spherical drag law is adopted to calculate the drag force coefficient of the biomass particles[37], and the shape factor of biomass particle was related to its volatile content, as presented in Table 2. For coal particles, it is widely acknowledged that the drag force can be accurately calculated using the spherical drag law[31, 38].

Due to the significant fraction of volatile matter in biomass, the effect of swelling during the biomass devolatilization process on the drag force should also be considered. In this work, the swelling coefficient for each type of biomass was experimentally obtained, and was calculated as the ratio of the average diameter of the char particles (obtained at a high heating rate in the IPFR reactor) to the average diameter of the initial torrefied biomass particles, the measured swelling coefficients of torrefied biomasses are presented in Table 2. The swelling coefficient of pulverized coal was selected as 1.1 according to the experimental studies of Fletcher[39].

\section{(c) NOx model}

Thermal NOx refers to the NOx formed via the high temperature oxidation of the atmospheric nitrogen in the combustion air. It is widely acknowledged that the formation rate of 
thermal NO is determined by the extended Zeldovich mechanisms[40]. The production of NOx from nitrogen-containing fuels results from the conversion of fuel-bound nitrogen to $\mathrm{NOx}$ during combustion. Fuel nitrogen is usually assumed to react via the intermediates of HCN and $\mathrm{NH}_{3}$, which are finally either oxidized into $\mathrm{NO}$ or reduced into $\mathrm{N}_{2}$ [41]. In this work, it was assumed that $90 \%$ of the volatile nitrogen from coal will be converted to $\mathrm{HCN}$, and the rest will form $\mathrm{NH}_{3}[42]$. For the biomass particles, it was assumed that $10 \%$ of $\mathrm{HCN}$ and $90 \%$ of $\mathrm{NH}_{3}$ were derived from the volatile nitrogen[43]. In addition, it was assumed that the nitrogen contained both in the coal char and the biomass char will be directly converted to NO due to the complex conversion mechanisms. Finally, prompt NOx was also considered in this work [44].

\section{Results and discussions}

\subsection{TG studies of torrefied biomasses}

The results of the devolatilization studies in the TG balance can be used to compare the reactivity of fuels. The weight loss curves of all of the biomass materials are compared in Figure 4a. The volatiles were released in the main weight loss step. As observed from the proximate analysis (see Table 1), the amount of released volatile matter reduced gradually from the raw PKS to TB1, TB2, and TB3. Furthermore, a slightly higher reactivity was observed in the raw PKS by considering the lower temperature at which the devolatilization begins. This was observed in the DTG curves of Figure 4b, in which the onset temperature did not vary significantly for the torrefied PKS. Generally, the earlier sub-peak of devolatilization was attributed to the decomposition of hemicellulose, which was the more reactive chemical component of the biomasses. Therefore, the delay of this sub-peak observed in the torrefied materials could be explained by a significant modification to the hemicelluloses structure during the torrefaction process. The main devolatilization peak was observed at approximately $360{ }^{\circ} \mathrm{C}$, which corresponds to the decomposition of cellulose. A higher peak indicated a higher content of 
cellulose. The decomposition of lignin occurs in a wider temperature range, starting from $250{ }^{\circ} \mathrm{C}$ and continuing to the end of the process for all of the torrefied PKS materials.

\section{Figure 4.}

\subsection{Kinetics of the torrefied biomasses}

In the two-competing-rate model, the first reaction (A1, E1, and V1) is used to calculate the devolatilization rate at the lower temperatures, whereas the second reaction (A2, E2, and V2) plays a dominant role at higher temperatures. Generally, the volatile matter yield is higher at high temperature than the standard volatile matter revealed by the proximate analysis. Once the preexponential factor and activation energy are known, the model calculates the release rate and the yields of volatile matter. For the torrefied PKS particles, the parameters for the kinetic rate of devolatilization and the char oxidation were obtained from the experimental data at high temperatures and high heating rates in the IPFR. The kinetics of the torrefied PKS are shown in Table 2. For the coal particles used in this study, the kinetic parameters of devolatilization were obtained from Li et al.[45], and the kinetics of the coal char oxidation were calculated using Hurt and Mitchell's correlations[46].

Table 2.

\subsection{Validation of the reference case}

The flames were photographed and video recorded using a CCD commercial photo camera (Sony DSC-V1) via the two observation windows. In this paper, the observed flame is referred to as the visible flame. The flame tests were performed with the coal particles, and thus the visible coal flame will be used to validate the combustion model.

To further understand the combustion performances when switching a pulverized coal-fired boiler to biomass operation, the combustion and flame characteristics of the torrefied biomass were studied numerically based on a laboratory-scale down-firing furnace under high temperature 
air conditions. In total 17 cases were simulated, and their detailed operating parameters are listed in Table 3.

\section{Table 3.}

The temperature profile, visible flame, and chemical flame of pulverized coal were compared to validate the used model, as shown in Figure 5, in which the temperature profile and the chemical flame were obtained based on the simulation results. The high temperature contour can approximately represent a luminous flame, and the high temperature zone is caused by the highly exothermic reaction that takes place. However, the flame cannot be described exactly based on the temperature profile, because the definition of the luminous flame boundary has always been challenging. Compared to the temperature profile and the visible images of the flame, the chemical flame provides a more accurate description of the flame by considering of flame front, lift-off distance, and maximum flame diameter. From Figure 5, the flame lift-off distance and flame profile of coal powders were similar when the chemical flame was compared with the visible flame.

Furthermore, the lift-off distances of the chemical flame and the visible flame were compared at various transport velocities, as shown in Figure 6. It can be observed that the lift-off distances of the chemical flame were in good agreement with that of the visible flame, and the flame lift-off distances progressively increased as the transport velocity increased. A larger difference was observed when the pulverized coal was injected by the transport air at a velocity of $30 \mathrm{~m} / \mathrm{s}$, which might be explained by the increase in the measured error, because a high flame propagation speed enhanced the fluctuation of the visible flame. Based on the above discussions, it could be concluded that chemical flame based on numerical results was reasonable for further studies of biomass flames.

Figure 5 . 
Figure 6.

\subsection{Effect of the torrefaction degree on the flame}

Generally, hemicellulose is decomposed during the biomass torrefaction process, and thus a high torrefaction degree usually refers to a small amount of volatile in remaining biomass. Four different types of solid fuel were studied: coal and three torrefied biomasses (TB1, TB2, and TB3) with different torrefaction degrees. The four cases (cases 1, 7, 8, and 9) were simulated with the same heat furnace capacity, transport air velocity, and particle size distribution. Figure 7 shows the effects of the fuel type on the flame position along the furnace height and the flame shape. It should be noted that the $0 \mathrm{~mm}$ height of the down-firing furnace is the fuel/air injection ports. Figure 7 indicates that the coal flame was closest to the fuel inlets, whereas all three torrefied flames moved to positions far from the fuel inlet, and the distance that the biomass flame moved was approximately the length of the coal flame, which is confirmed by the experimental results reported by Lu et al.[3]. The results might be caused by the differences in the drag forces imposed on the biomass particles and coal particles. Due to the lower density of biomass, an enhanced drag force on the biomass particles could cause a late release of volatile matter and thus delay the ignition of the fuel-air mixture. This conclusion further explains the results indicating that the major combustion zone of the biomass that moved towards the furnace exit in a pulverized co-firing boiler, as reported by Li et al.[10].

Moreover, it was found that the torrefied biomass flame had a wider diameter than coal flame, a similar experimental result was reported by Ballester et al.[12]. It is interesting to note that, Figure 7 shows the biomass flame volume increased as the volatile content increased for all of the studied torrefied biomasses. A clear reason is that a higher volatile content improved the diffusion of the combustible gases, causing a larger flame volume and a large flame diameter; in addition, volatile and its preliminary combustion products enhances the gas phase diffusion from 
near-flame zone to a wider zone. At high rates of devolatilization, the volatiles can effectively surround the coal particle against the oxygen attack. According to Krazinski et al. [47], the volatiles are released from the surface of the particles and subsequently combusted with a diffusion flame, and the volatiles are released rapidly in the front of the flame; in contrast, the devolatilization rate is no longer significant in the tail of flame, which may also affect the flame lift-off distance. Meanwhile, it should be noticed that the predicted peak flame temperature of the coal powders was higher than that of the biomass powders, and the peak temperatures of the torrefied biomasses decreased as the volatile contents increased. The predicted peak temperatures of coal, TB3, TB2, and TB1 under the studied conditions is $2186{ }^{\circ} \mathrm{C}, 2007{ }^{\circ} \mathrm{C}, 1963{ }^{\circ} \mathrm{C}$, and 1843 ${ }^{\circ} \mathrm{C}$, respectively. The temperature of flame formed around the particles depends on the heating value of gas releasing from particles. Therefore, the delay of the high temperature flame zone, the changes in the flame volumes with volatile content of the fuel, and the relatively lower peak flame temperature must be taken into considered when combusting biomass in an existing pulverized coal boiler.

Figure 7.

\subsection{Effect of the oxygen concentration of the oxidizer on flame}

Volumetric combustion is characterized as an extension of the HiTAC technology for solid fuels with typical advantages, including the dilution of the oxygen by an enhanced flue gas internal recirculation, uniformity of both the temperature and species concentrations, and a lower peak flame temperature. In this work, to understand volumetric combustion properties of torrefied biomass particles, the flame characteristics of a torrefied biomass (TB2) were studied numerically when varying the oxygen concentrations (cases 10,15, 16, and 17). The oxygen concentration was adjusted by using a mixture of steam and air. The effect of oxygen concentration in the oxidizer on the flame position along the furnace height and the flame shape is shown in Figure 8. The flame volume and flame length increased as the oxygen concentration 
in oxidizer was reduced, whereas the flame lift-off distance and maximum flame diameter changed only slightly for all of the studied cases. This is because the oxygen concentrations were adjusted by replacing part of the air with high temperature steam, and the combustible species released after devolatilization diffused in a wider zone of the furnace before being completely combusted. Therefore, the combustion volume was larger for the cases with diluted oxygen concentrations than that with normal air combustion. In addition, according to the simulation results, the peak temperatures of biomass decreased as expected with deceasing oxygen concentrations, which is a common feature of volumetric combustion with low oxygen concentrations. The predicted peak temperature of TB2 at oxygen fractions of $21 \%, 17.9 \%$, $13.9 \%$ and $11.8 \%$ is $1913{ }^{\circ} \mathrm{C}, 1649^{\circ} \mathrm{C}, 1387^{\circ} \mathrm{C}$, and $1220^{\circ} \mathrm{C}$, respectively.

Figure 8.

The benefits of low peak temperature and low oxygen concentration have been demonstrated in various industrial combustion applications, because it is an effective option to reduce NOx and improve boiler efficiency. To understand the relationship between the flame length or the flame volume and the NOx emissions, the performances of the NOx emissions under different oxygen concentration conditions have also been studied. Figure 9 indicates that the oxygen concentration strongly influences the NO emission and the flame length, and a lower oxygen concentration always corresponds to a longer flame length and a lower NO emission both for biomass and coal. According to the predicted results, the lowest amounts of $\mathrm{NO}$ produced are $248 \mathrm{mg} / \mathrm{Nm}^{3}$ for biomass and $515 \mathrm{mg} / \mathrm{Nm}^{3}$ for coal when the oxidizer contained $11.8 \%$ oxygen. Accordingly, all of the measured NOx emissions from coal showed a similar trend with the predicted values, which further confirmed the reasonableness of the numerical models and method adopted in this study. Although Figure 9 shows that the maximum amount of NOx was higher than $1400 \mathrm{mg} / \mathrm{Nm}^{3}$ in case of normal air combustion, was mainly due to the injection of the fuel and the oxidizer without applying any low-NOx technology, such as air-staging and fuel-staging. 
According to the results, it could be concluded that a longer flame length or a bigger flame volume is beneficial for NOx reduction. There might be several reasons to explain these results. The first important reason is that the whole combustion zone was operated under substoichiometric conditions with an excess air ratio less than one, which not only reduced the maximum flame temperature, but also prevented the formation of nitrogen oxides from fuelbound nitrogen. Furthermore, the lower $\mathrm{O}_{2}$ partial pressure and lower maximum flame temperature under lower oxygen combustion conditions inhibited the formation of thermal NO. Third, because the triatomic species $\mathrm{H}_{2} \mathrm{O}$ is not transparent to radiation, it substantially increased the absorptivity and emissivity of the flue gas, and as a result, an increased $\mathrm{H}_{2} \mathrm{O}$ concentration may have affected the heat transfer and flame temperature inside the furnace, which could in turn affect the formation of NO [48]. The results further confirmed that volumetric combustion with a flame as large as furnace volume could be featured as a promising low-NOx combustion technology for biomass combustion.

Figure 9 .

\subsection{Effect of the transport air velocity on flame}

The transport air velocity is important in the combustion processes of coal and biomass powders, and can partly control the global combustion rates. In this work, a torrefied biomass (TB2) was studied. Three cases with different transport air velocities of $9 \mathrm{~m} / \mathrm{s}, 20 \mathrm{~m} / \mathrm{s}$, and 30 $\mathrm{m} / \mathrm{s}$ (cases 9, 10, and 11) were simulated at the same fuel feed rate and same particle size distribution. The transport air velocities were varied by changing the amounts of the air flow rates. The change in the flame position along the furnace height and the change in the flame shape with varying transport air velocities are shown in Figure 10. Obviously, the transport air velocity had significant effects on both the flame volume and the flame length, and a longer flame was observed at a lower transport air velocity. Under the high temperature combustion 
conditions, the operating temperature of the furnace is high (above $1400^{\circ} \mathrm{C}$ ), so that volatile combustion occurs at high Damköhler numbers $(\mathrm{Da}>>1)$; therefore, the combustion rates of the volatiles are mainly controlled by the diffusion of oxygen. At lower transport air velocities, the diffusion rate of oxygen is slower than that under a higher transport air velocity. However, the flame front decreased as the transport air velocities increased, and the flame lift-off distance increased simultaneously. Furthermore, the transport air velocity had negligible effects on the maximum flame diameter because the maximum flame diameters were almost the same for the three cases, as shown in Figure 10, which might further confirm that the maximum flame diameter is mainly affected by the volatile contents of the fuels. In addition, according to the numerical simulation, the predicted peak temperatures of TB2 at transport velocities of $9 \mathrm{~m} / \mathrm{s}, 20$ $\mathrm{m} / \mathrm{s}$, and $30 \mathrm{~m} / \mathrm{s}$ is $1855^{\circ} \mathrm{C}, 1913{ }^{\circ} \mathrm{C}$, and $1963{ }^{\circ} \mathrm{C}$, respectively. A possible explanation is that the high transport air velocity enhanced the diffusion of the oxidizer onto the char surface and resulted in a high char oxidation rate inside the flame. According to the above discussion, a relatively lower fuel injection velocity is suggested when combusting biomass in an existing pulverized coal furnace, meanwhile, it indicates that the discrete concentration in pneumatic transport flow would be increased to maintain the same heat capacity. However, the residence time, combustion rate, furnace temperature and economical factors should be considered altogether to determine a reasonable transport air velocity; for example, a lower flow rate usually means a lower combustion rate, whereas a high flow rate normally accompanies a high erosion rate.

Figure 10.

\subsection{Effect of particle size on flame}

Particle size is an important parameter during the pulverized fuel combustion process, and thus the effects of particle size on combustion performances have been studied widely. Typically, it is generally acknowledged that heterogeneous reactions are controlled by diffusion for particles 
of diameter larger than $0.1 \mathrm{~mm}$ when surrounding temperatures are higher than $1000 \mathrm{~K}$; while the heterogeneous reactions of even $0.01 \mathrm{~mm}$ sized particles are controlled by diffusion when the surrounding temperature exceeds $2000 \mathrm{~K}$ [47].

To investigate the influence of particle size on high temperature flames, three cases (cases 12, 13, and 14) have been studied with three different uniform particle sizes $(0.1 \mathrm{~mm}, 0.2 \mathrm{~mm}$, and $0.3 \mathrm{~mm}$, respectively). Larger biomass particles were not investigated in this work because of the limitation of the fuel lance diameter. The effect of particle size on the flame position along the furnace height and the flame shape is shown in Figure 11. It can be observed that the flame positions gradually moved toward the furnace exit as particle size increased. This result could be explained by the longer residence time needed for the complete pyrolysis of a larger particle, which would thus delay the burnout of the char. For each type of solid fuel, the efflux rate of the volatile was found to vary with the particle sizes. For example, Howard and Essenhigh reported that coal particles larger than $65 \mu \mathrm{m}$ do not react heterogeneously during the rapid devolatilization process[49]. Furthermore, according to the predicted results, the peak temperature for TB2 consisting of uniform particle sizes of $0.1 \mathrm{~mm}, 0.2 \mathrm{~mm}$, and $0.3 \mathrm{~mm}$ is 1984 ${ }^{\circ} \mathrm{C}, 1881{ }^{\circ} \mathrm{C}$, and $1582{ }^{\circ} \mathrm{C}$, respectively, which indicates that a small particle is quickly combusted completely. In addition, the results showed that the maximum flame diameter was almost the same for the studied particle sizes; therefore, it could be concluded that particle size had negligible effects on the maximum flame diameter.

Figure 11.

\section{Conclusions}

In this work, the combustion and flame characteristics of torrefied biomass have been studied numerically in a laboratory-scale down-firing furnace under higher temperature air conditions. Three torrefied biomasses obtained from same raw PKS material with torrefaction 
degrees of $10 \%, 20 \%$ and $30 \%$ of volatile content released on a dry basis were studied. Finally, the effects of the torrefaction degree, oxygen concentration, transport air velocity, and particle size on the flame positions and flame shapes, and peak flame temperatures were discussed.

The results mainly showed that the enhanced drag force on the biomass particle caused a late release of volatile matter and resulted in a delay in the ignition of the fuel-air mixture, and the maximum flame diameter was mainly affected by the volatile content of materials. Furthermore, a lower oxygen concentration always corresponded to a larger flame volume, a lower peak temperature, and a lower NO emission. A longer flame was observed when the transport air velocity was lower, and the flame positions gradually moved toward the furnace exit with increasing of particle sizes. The results could be used to design a biomass combustion chamber and/or provide an operational reference for the co-firing performances in a coal-fired boiler. However, a series of relative experiments also should be carried out in the future to obtain further details of the biomass flames.

\section{Acknowledgements}

The authors would like to thank EU/KIC-Innoenergy and the BRISK project for the financial support of this work. Author Jun Li also acknowledge the financial supports by the China Scholarship Council (CSC).

\section{References}

1. http://www.europeanclimate.org/documents/Biomass report - Final.pdf

2. http://www.erec.org/fileadmin/erec docs/Projcet Documents/RES2020/SWEDEN RES Pol icy Review Final.pdf

3. G. Lu; Y. Yan; S. Cornwell; M. Whitehouse; G. Riley, Fuel 87 (7) (2008) 1133-1140

4. B. Arias; C. Pevida; J. Fermoso; M. G. Plaza; F. Rubiera; J. J. Pis, Fuel Processing Technology 89 (2) (2008) 169-175.

5. J. M. Jones; T. G. Bridgeman; L. I. Darvell; B. Gudka; A. Saddawi; A. Williams, Fuel Processing Technology 101 (0) (2012) 1-9.

6. D. Tapasvi; R. Khalil; G. Várhegyi; Ø. Skreiberg; K.-Q. Tran; M. Grønli, Energy \& Fuels 27 (2) (2013) 1050-1060.

7. M. J. C. van der Stelt; H. Gerhauser; J. H. A. Kiel; K. J. Ptasinski, Biomass and Bioenergy 35 (9) (2011) 3748-3762. 
8. M. J. Prins; K. J. Ptasinski; F. J. J. G. Janssen, Journal of Analytical and Applied Pyrolysis 77 (1) (2006) 35-40.

9. V. Repellin; A. Govin; M. Rolland; R. Guyonnet, Biomass and Bioenergy 34 (7) (2010) 923-930.

10. J. Li; A. Brzdekiewicz; W. Yang; W. Blasiak, Applied Energy 99 (0) (2012) 344-354.

11. A. B. P. Bergman, R. Zwart and J. Kiel, ECN-C-05-013 (2005)

12. J. Ballester; J. Barroso; L. M. Cerecedo; R. Ichaso, Combustion and Flame 141 (3) (2005) 204-215.

13. P. Molcan; G. Lu; T. L. Bris; Y. Yan; B. Taupin; S. Caillat, Fuel 88 (12) (2009) 2328-2334.

14. M. Mandø; L. Rosendahl; C. Yin; H. Sørensen, Fuel 89 (10) (2010) 3051-3062.

15. C. Yin; L. Rosendahl; S. K. Kær, Fuel Processing Technology 98 (0) (2012) 65-73.

16. S. R. Gubba; L. Ma; M. Pourkashanian; A. Williams, Fuel Processing Technology 92 (11) (2011) 2185-2195.

17. J. Pallarés; A. Gil; C. Cortés; C. Herce, Fuel Processing Technology 90 (10) (2009) 1207-1213.

18. E. Karampinis; N. Nikolopoulos; A. Nikolopoulos; P. Grammelis; E. Kakaras, Applied Energy 97 (0) (2012) 514-524.

19. S. R. Gubba; D. B. Ingham; K. J. Larsen; L. Ma; M. Pourkashanian; H. Z. Tan; A. Williams; H. Zhou, Fuel Processing Technology 104 (0) (2012) 181-188.

20. L. Ma; J. M. Jones; M. Pourkashanian; A. Williams, Fuel 86 (12-13) (2007) 1959-1965.

21. J. Li; W. Yang; W. Blasiak; A. Ponzio, Fuel 102 (0) (2012) 624-633.

22. Hiroshi Tsuji, A. K. Gupta,Toshiaki Hasegawa, Masashi Katsuki, Ken Kishimoto and Mitsunobu Morita High temperature air combustion : from energy conservation to pollution reduction, CRC Press 2002.

23. G. Cho; G. Moon; D. Jeong; C. Bae, Fuel 88 (6) (2009) 1042-1048.

24. S.-R. Wu; C.-H. Chen; I. L. Chung; H.-T. Lee, Fuel 90 (8) (2011) 2639-2644.

25. V. K. Arghode; A. K. Gupta, Applied Energy 88 (3) (2011) 963-973.

26. H. Zhang; G. Yue; J. Lu; Z. Jia; J. Mao; T. Fujimori; T. Suko; T. Kiga, Proceedings of the Combustion Institute 31 (2) (2007) 2779-2785.

27. N. Schaffel-Mancini; M. Mancini; A. Szlek; R. Weber, Energy 35 (7) (2010) 2752-2760.

28. E. Biagini; M. Simone; L. Tognotti, Proceedings of the Combustion Institute 32 (2) (2009) 20432050.

29. W. Yang; W. Blasiak, Energy 30 (2-4) (2005) 385-398.

30. J. B. Howard; R. H. Essenhigh, Industrial \& Engineering Chemistry Process Design and Development 6 (1) (1967) 74-84.

31. Ansys, Ansys fluent 12.0-Theory guide, 2009.

32. B. E. Launder; D. B. Spalding, Computer Methods in Applied Mechanics and Engineering 3 (2) (1974) 269-289.

33. H. Kobayashi; J. B. Howard; A. F. Sarofim, Symposium (International) on Combustion 16 (1) (1977) 411-425.

34. M. M. Baum; P. J. Street, Combustion Science and Technology 3 (5) (1971) 231-243.

35. M. A. Field, Combustion and Flame 13 (3) (1969) 237-252.

36. M. E. Morgan; P. A. Roberts, Fuel Processing Technology 15 (0) (1987) 173-187.

37. A. Haider; O. Levenspiel, Powder Technology 58 (1) (1989) 63-70.

38. S. A. Morsi; A. J. Alexander, Journal of Fluid Mechanics 55 (02) (1972) 193-208

39. T. H. Fletcher, Fuel 72 (11) (1993) 1485-1495.

40. D. W. G. M.A. Field, B.B. Morgan and P.G.W. Hawksley in: Combustion of Pulverised Coal, BCURA, London, 1967.

41. G. G. De Soete, Symposium (International) on Combustion 15 (1) (1975) 1093-1102.

42. F. Winter; C. Wartha; G. Löffler; H. Hofbauer, Symposium (International) on Combustion 26 (2) (1996) 3325-3334.

43. H. Liu; B. M. Gibbs, Fuel 81 (3) (2002) 271-280.

44. C. P. Fenimore, Combustion and Flame 26 (0) (1976) 249-256.

45. J. Li; R. Jankowski; M. Kotecki; W. Yang; D. Szewczyk; A. Brzdekiewicz; W. Blasiak, Energy \& Fuels 26 (2) (2012) 926-937.

46. R. H. Hurt; R. E. Mitchell, Symposium (International) on Combustion 24 (1) (1992) 1243-1250.

47. J. L. Krazinski; R. O. Buckius; H. Krier, Progress in Energy and Combustion Science 5 (1) (1979) 31-71. 
48. L. Chen; S. Z. Yong; A. F. Ghoniem, Progress in Energy and Combustion Science 38 (2) (2012) 156-214.

49. J. B. Howard; R. H. Essenhigh, Symposium (International) on Combustion 11 (1) (1967) 399-408. 


\section{Tables}

Table1. Analysis data of pulverized biomass powder

\begin{tabular}{llllll}
\hline Items & Units & TB1 & TB2 & TB3 & Coal \\
\hline Torrefaction degree & $\%$ & 10 & 20 & 30 & $/$ \\
Proximate analysis & & & & & \\
Moisture (as received) & $w t \%$ & 5.8 & 5.6 & 5.1 & 6.7 \\
Ash (dry) & $w t \%$ & 6.56 & 7.31 & 8.5 & 11.10 \\
Volatile (dry) & $w t \%$ & 66.53 & 61.87 & 49.92 & 19.41 \\
Fixed carbon (dry) & $w t \%$ & 26.91 & 30.82 & 41.58 & 62.79 \\
LHV (dry) & $M J / k g$ & 20.5 & 20.9 & 25.0 & 28.95 \\
Ultimate analysis (dry ash free) & $w t \%$ & 54.30 & 55.43 & 60.67 & 86.27 \\
C & $w t \%$ & 5.07 & 4.90 & 4.33 & 4.54 \\
H & $w t \%$ & 33.52 & 31.83 & 25.90 & 7.04 \\
O & $w t \%$ & 0.50 & 0.50 & 0.57 & 1.70 \\
$\mathrm{~N}$ & $w t \%$ & 0.05 & 0.04 & 0.03 & 0.45 \\
S & & & & & \\
\hline
\end{tabular}

Table 2. Kinetic parameters for torrefied biomass and coal particles

\begin{tabular}{|c|c|c|c|c|}
\hline & TB1 & TB2 & TB3 & Coal $^{[39,45,46]}$ \\
\hline \multicolumn{5}{|c|}{ Devolatilization kinetics (at high heating rates) } \\
\hline $\mathrm{A} 1\left(\mathrm{~s}^{-1}\right)$ & $6.40 \mathrm{E}+03$ & $5.48 \mathrm{E}+03$ & $3.27 \mathrm{E}+03$ & $3.7 \mathrm{E}+5$ \\
\hline A2 $\left(\mathrm{s}^{-1}\right)$ & $1.98 \mathrm{E}+05$ & $2.15 \mathrm{E}+07$ & $2.10 \mathrm{E}+07$ & $1.46 \mathrm{E}+13$ \\
\hline E1 $(\mathrm{kJ} / \mathrm{mol})$ & 57.0 & 59.8 & 60.2 & 73.7 \\
\hline $\mathrm{E} 2(\mathrm{~kJ} / \mathrm{mol})$ & 145 & 147 & 159 & 251 \\
\hline V1 & 0.67 & 0.62 & 0.499 & 0.3 \\
\hline $\mathrm{V} 2$ & 0.74 & 0.70 & 0.50 & 0.8 \\
\hline Mean error ${ }^{*}(\%)$ & 4.5 & 4.5 & 4.5 & / \\
\hline \multicolumn{5}{|l|}{ Char oxidation kinetics } \\
\hline$A\left(s^{-1}\right)$ & 56 & 56.3 & 56.3 & 0.91 \\
\hline $\mathrm{Ea}(\mathrm{kJ} / \mathrm{mol})$ & 77 & 78 & 79 & 103 \\
\hline Shape factor & 0.53 & 0.54 & 0.58 & 1 \\
\hline Swelling coefficients & 1.0 & 1.0 & 1.8 & 1.1 \\
\hline
\end{tabular}

* calculated as the mean of absolute differences between model and experimental results of torrefied biomass from high heating rate tests in the IPFR: error $=\sum_{n} \frac{\left|X_{\text {mod }}-X_{\text {exp }}\right|}{n} \cdot 100 \%$ 
Table 3. The operation conditions of all cases

\begin{tabular}{|c|c|c|c|c|c|c|c|c|}
\hline \multirow[b]{2}{*}{ Case } & \multicolumn{3}{|r|}{ Fuel } & \multicolumn{2}{|c|}{ Transport air } & \multicolumn{3}{|c|}{ Secondary air } \\
\hline & $\begin{array}{l}\text { Fuel } \\
\text { type }\end{array}$ & $\begin{array}{l}\text { Feed } \\
\text { rates } \\
(\mathrm{kg} / \mathrm{h})\end{array}$ & $\begin{array}{l}\text { Particle size distribution } \\
(\mu \mathrm{m})\end{array}$ & $\begin{array}{l}\text { Velocity } \\
(\mathrm{m} / \mathrm{s})\end{array}$ & $\begin{array}{l}\text { Temp. } \\
\left({ }^{\circ} \mathrm{C}\right)\end{array}$ & $\begin{array}{c}\text { Oxygen } \\
\text { concentrations } \\
(\text { vol } \%)\end{array}$ & $\begin{array}{l}\text { Flow } \\
\text { rates } \\
(\mathrm{kg} / \mathrm{h})\end{array}$ & $\begin{array}{l}\text { Temp. } \\
\left({ }^{\circ} \mathrm{C}\right)\end{array}$ \\
\hline 1 & coal & 5.00 & R.-R. (avg. 61.7, max. 300 ) & 30 & 120 & $21 /$ (Air) & 115 & 1150 \\
\hline 2 & coal & 5.00 & R.-R. (avg. 61.7, max. 300 ) & 20 & 120 & $21 /$ (Air) & 115 & 1150 \\
\hline 3 & coal & 5.00 & R.-R. (avg. 61.7, max. 300 ) & 9 & 120 & $21 /$ (Air) & 115 & 1150 \\
\hline 4 & coal & 5.00 & R.-R. (avg. 61.7, max. 300 ) & 20 & 120 & $17.9 /($ Air+Steam $)$ & 115 & 1150 \\
\hline 5 & coal & 5.00 & R.-R. (avg. 61.7, max. 300 ) & 20 & 120 & $13.9 /($ Air + Steam $)$ & 115 & 1150 \\
\hline 6 & coal & 5.00 & R.-R. (avg. 61.7, max. 300 ) & 20 & 120 & $11.8 /($ Air+Steam $)$ & 115 & 1150 \\
\hline 7 & TB1 & 6.61 & R.-R. (avg. 61.7, max. 300 ) & 30 & 90 & $21 /$ (Air) & 115 & 1150 \\
\hline 8 & TB2 & 6.73 & R.-R. (avg. 61.7, max. 300 ) & 30 & 90 & $21 /$ (Air) & 115 & 1150 \\
\hline 9 & TB3 & 5.62 & R.-R. (avg. 61.7, max. 300 ) & 30 & 90 & $21 /$ (Air) & 115 & 1150 \\
\hline 10 & TB2 & 6.73 & R.-R. (avg. 61.7, max. 300 ) & 20 & 90 & $21 /$ (Air) & 115 & 1150 \\
\hline 11 & TB2 & 6.73 & R.-R. (avg. 61.7, max. 300 ) & 9 & 90 & $21 /$ (Air) & 115 & 1150 \\
\hline 12 & TB2 & 6.73 & uniform-100 & 20 & 90 & $21 /$ (Air) & 115 & 1150 \\
\hline 13 & TB2 & 6.73 & uniform-200 & 20 & 90 & $21 /$ (Air) & 115 & 1150 \\
\hline 14 & TB2 & 6.73 & uniform-300 & 20 & 90 & $21 /$ (Air) & 115 & 1150 \\
\hline 15 & TB2 & 6.73 & R.-R. (avg. 61.7, $\max .300$ ) & 20 & 90 & $17.9 /($ Air+Steam $)$ & 115 & 1150 \\
\hline 16 & TB2 & 6.73 & R.-R. (avg. 61.7, max. 300 ) & 20 & 90 & $13.9 /($ Air+Steam $)$ & 115 & 1150 \\
\hline 17 & TB2 & 6.73 & R.-R. (avg. 61.7, max. 300 ) & 20 & 90 & $11.8 /($ Air+Steam $)$ & 115 & 1150 \\
\hline
\end{tabular}

Note: R.-R. represents Rosin-Rammler size distribution with spread parameter of 4.21 .

\section{Figure captions}

Figure 1. Van Krevelen diagram for different solid fuels (Note: the reference data of bituminous, subbituminous coal and wood are from IFRF solid fuel database)

Figure 2. Scheme and selected geometry of the test furnace

Figure 3. Chemical flame scheme of solid fuels

Figure 4. Comparisons of torrefied masteries TG (a) and DTG (b)

Figure 5. Comparisons among chemical flame, temperature profile and visible flame

Figure 6. Comparison of chemical flame lift-off distance and visible flame lift-off distance

Figure 7. Flame shapes and flame positions along furnace height with various fuel types

Figure 8. Flame shapes of TB2 and flame positions along the furnace height with various oxygen concentrations

Figure 9. Effects of oxygen concentrations on NO emissions and flame lengths

Figure 10. Flame shapes for TB2 and flame positions along furnace height with various primary air velocities

Figure 11. Flame shapes for TB2 and flame positions along the furnace height with various particle sizes 